Journal of

Women's Health and Gynecology

\title{
Impact of Body Mass Index on Prognosis for Breast Cancer Patients
}

\author{
Fei Tan ${ }^{1, *}$, Hong Xiao ${ }^{2}$, Sriharsha Gummadi ${ }^{3}$, Leonidas G. Koniaris ${ }^{4}$, Jason David Feldman ${ }^{5}$, Askal \\ Ayalew Ali ${ }^{6}$, George Adunlin ${ }^{7}$, Youjie Huang ${ }^{8}$
}

${ }^{1}$ Department of Mathematical Sciences, Indiana University-Purdue University Indianapolis 402 N. Blackford Street, LD 224S, Indianapolis, IN 46202-3216

${ }^{2}$ University of Florida, College of Pharmacy, Pharmaceutical Outcomes \& Policy, 1225 Center Drive, Gainesville, FL

${ }^{3}$ Department of Surgery, Lankenau Medical Center, 100 E Lancaster Ave, MOB South Suite 422, Wynnewood, PA

${ }^{4}$ School of Medicine, Indiana University, Indianapolis, IN

${ }^{5}$ Office of Infectious Disease, Washington State Department of Health, P.O. Box 47841, Olympia, WA 98504

${ }^{6}$ Division of Economic, Social and Administrative Pharmacy, College of Pharmacy and Pharmaceutical Sciences, Florida A\&M University

${ }^{7}$ Department of Health Behavior and Policy, Virginia Commonwealth University School of Medicine, Richmond, VA

${ }^{8}$ Lorie Kayler and Associates, 6840 Kew Gardens Way, Cumming, GA 30040

${ }^{\star}$ Corresponding author: Fei Tan, Department of Mathematical Sciences, Indiana University-Purdue University Indianapolis 402 N. Blackford Street, LD 224S, Indianapolis, IN 46202-3216

Received Date: March 13, 2017; Accepted Date: April 04, 2017; Published Date: April 06, 2017

Citation: Fei Tan, et al. (2017) Impact of Body Mass Index on Prognosis for Breast Cancer Patients. J Womens Health Gyn 4: $1-11$.

\begin{abstract}
This study investigates the impact of body mass index (BMI) on the prognosis for patients with breast cancer within the context of race (African-American versus Caucasian) and ethnicity (Hispanic versus Non-Hispanic). Overall, this study included 1,368 female breast cancer patients diagnosed between 2007 and 2010 with electronic medical record data accrued from a large Florida hospital network. Non-Hispanic black patients comprised $8.77 \%$ of the cohort and Hispanic patients made up $7.56 \%$. Multivariate analysis revealed that breast cancer death rate was increased over 2.6-fold for underweight patients ubiquitously, regardless of race or ethnicity. Patients overweight or obese did not have an increased hazard rate compared to those of normal weight. Importantly, the mechanism for the poorer prognosis for underweight patients needs to be defined. We suggest the use of a low BMI as a high-risk factor for breast-cancer mortality in all racial and ethnic populations.
\end{abstract}

Keywords: Breast Cancer Prognosis; Body Mass Index; Race; Ethnicity

(C)2017 The Authors. Published by the JScholar under the terms of the Creative Commons Attribution License http://creativecommons.org/licenses/ by/3.0/, which permits unrestricted use, provided the original author and source are credited. 


\section{Introduction}

Breast cancer is the most common malignancy affecting women, representing $16 \%$ of all cancers [1]. In the United States, lifetime risk for breast cancer development is approximately $12 \%$ [2]. Although great improvements in disease-free survival have been obtained, as many as $2.86 \%$ of all women in the U.S will die from primary breast cancer (calculated over the 2003 - 2005 period). Breast cancer is the second most common cause of cancer-related death in women [3]. It remains critical to identify high-risk patient subgroups to improve patient outcomes while not subjecting those patients with excellent prognosis to unnecessary therapies.

The literature notes that African-American women have worse health outcomes after a diagnosis of breast cancer compared with their Caucasian counterparts [4]. Several studies have attempted to identify independent risk factors for the worse prognosis for African-American women, including later stage of diagnosis and treatment options. With the growing prevalence of obesity in the U.S. (32.2\% of men and 35.5\% of women), it is impossible to ignore the role of metabolic status in breast cancer prognosis, particularly within the context of race [5]. However, establishing a single model relationship between body mass index (BMI) and breast malignancy remains a point of contention. Historically, it has been suggested that high BMI is a risk factor for breast cancer development and increased mortality [5-13]. However, more recently, studies have suggested increased BMI may also be protective from mortality [14-18]. The purpose of this study was to determine the impact of BMI on outcomes for patients with breast cancer, examining a relatively large cohort of diverse Florida women, representing the dynamics characteristic of the broader U.S. patient population.

\section{Methods}

\section{Data collection}

The dataset created for this study is intended to advance patient-centered outcomes research on complex patients within the AHRQ Multiple Chronic Conditions Research Network [19]. This study was designed to compare patient survival trends using a dataset of hospital patient data linked with state cancer registry data. The dataset was created through a partnership between the Florida Department of Health, the Florida Cancer Data System (FCDS), academic researchers from Florida A\&M University, the University of Miami and a large Florida hospital network. The hospital network provided patient electronic medical records (EMRs). EMRs contain patient medical and demographic information in greater detail than data elements routinely collected by FCDS, the state cancer registry. Invasive breast cancer patients were identified among patients whose principal diagnosis or a secondary diagnosis code was International Classification of Diseases (ICD-9-CM) code between 174.0 and 174.9. The EMR records of invasive breast cancer patients were then linked to the central cancer registry data using unique patient identifiers.
Study subjects in this project were restricted to female breast cancer patients with diagnosis and/or treatment data from within the partner hospital system between 2007 and 2010 . Overall, 1,368 female breast cancer patients for whom immunohistochemistry biomarker and BMI data were available were identified and included for this study. This study was approved by the Florida Department of Health Institutional Review Board.

\section{Statistical analysis}

In this study, BMI was measured when patients were admitted for treatments. The BMI cut-off points we used to define underweight, normal, overweight, class I obese, class II obese, and class III obese were 19, 25, 30, 35, 40, with lower end included in the interval. The study cohort was divided into four (level 1-level 4) socioeconomic groups (SEG) and one unknown group based on the proportion of population under poverty level in the Census Tract where an individual lived at the time of diagnosis. The Elixhauser Index was used to identify major coexisting conditions based on the ICD-9 code of inpatient and outpatient administrative data [20]. Age at diagnosis was used as a proxy for menopausal status.

The analysis focused on cause-specific survival from breast cancer diagnosis to death due to breast cancer. Patients who died due to other reasons or were alive at the end of the study were statistically censored, allowing for a complex survival analysis for death due to breast cancer [21,22]. Descriptive statistics, including sample mean and sample proportion were applied to summarize patient characteristics. Population means were compared using $\mathrm{T}$ tests, while associations between categorical variables were assessed using $\chi 2$ tests. Within the bivariate analyses, survival probability over time was estimated for BMI and race/ethnicity categories using the Kaplan-Meier estimation method and tested using the log-rank test.

In order to study the adjusted BMI effect, multivariate survival analysis adjusting for confounders was also carried out using the Cox model. Specifically, the multivariate model included BMI, age at diagnosis, race/ethnicity, social economic status, marital status, health insurance, total comorbidity, triple negative marker status, histology information, treatment information, tumor grade at diagnosis, stage at diagnosis, tumor size, number of positive nodes identified, and total number of nodes examined. Interactions between BMI and race/ethnicity were also included in the multivariate analyses to examine existence of additional disadvantageous low BMI effect associated with Non-Hispanic black and Hispanic populations. To assess whether the effect of BMI or any significant covariate differed between the pre- and post-menopause subsamples in our data, the interaction between age at diagnosis and BMI with other significant covariates were tested. 
To formally assess whether the adjusted BMI effect was different across stage levels after adjusting for effect of other covariates (e.g. whether an increased death rate of being underweight existed for both patients diagnosed with regional or distant stage and patients with localized stage), the interaction between BMI and stage of diagnosis was tested. Hazard ratios were calculated for all variables in the model. The statistical analyses were conducted using SAS/STAT ${ }^{\varpi}$ software, Version 9.3 of the SAS System for Windows (Cary, North Carolina).

\section{Results}

\section{Demographic Profile}

The study cohort consisted of 1,368 female breast cancer patients diagnosed and treated between 2007 and 2010 where 106 patients died due to breast cancer during the study. Table 1 presents descriptive statistics for the demographic profile of the cohort, tested across non-underweight versus underweight $(\mathrm{BMI}<19)$.

Table 1: Patient characteristics and relation with underweight $(\mathrm{N}=1,368)$

\begin{tabular}{|c|c|c|c|c|c|}
\hline Variable & & Percentage & Non-underweight* & Underweight* & P-Value \\
\hline \multirow[t]{6}{*}{ BMI } & Under weight & 4.02 & & & \\
\hline & Normal & 33.04 & & & \\
\hline & Overweight & 29.68 & & & \\
\hline & Obese I & 18.20 & & & \\
\hline & Obese II & 8.99 & & & \\
\hline & Obese III & 6.07 & & & \\
\hline \multirow[t]{2}{*}{ Age at dx } & Age at $\mathrm{dx}<=50$ & 25.66 & 25.29 & 34.55 & 0.1546 \\
\hline & Age at dx > 50 & 74.34 & 74.71 & 65.45 & \\
\hline \multirow[t]{3}{*}{ Race/Ethnicity } & NH white & 83.67 & 83.62 & 84.91 & 0.6570 \\
\hline & NH black & 8.77 & 8.90 & 5.66 & \\
\hline & Hispanic & 7.56 & 7.48 & 9.43 & \\
\hline \multirow{5}{*}{$\begin{array}{l}\text { Social economic } \\
\text { status }^{* *}\end{array}$} & SEG 1 & 13.60 & 13.33 & 20.00 & 0.2308 \\
\hline & SEG 2 & 33.48 & 33.59 & 30.91 & \\
\hline & SEG 3 & 30.34 & 30.77 & 20.00 & \\
\hline & SEG 4 & 20.83 & 20.64 & 25.45 & \\
\hline & Unknown & 1.75 & 1.68 & 3.64 & \\
\hline \multirow[t]{3}{*}{ Married } & Single & 45.32 & 45.16 & 49.09 & 0.8385 \\
\hline & Married & 51.17 & 51.33 & 47.27 & \\
\hline & Unknown & 3.51 & 3.50 & 3.64 & \\
\hline \multirow[t]{5}{*}{ Insurance } & Not insured & 3.00 & 2.89 & 5.45 & 0.6711 \\
\hline & Medicaid & 8.11 & 8.00 & 10.91 & \\
\hline & Medicare & 32.68 & 32.75 & 30.91 & \\
\hline & Private insurance & 53.80 & 54.00 & 49.09 & \\
\hline & Unknown & 2.41 & 2.36 & 3.64 & \\
\hline Total comorbidity & & $0.65(1.29)$ & $0.65(1.31)$ & $0.49(0.96)$ & 0.2330 \\
\hline
\end{tabular}

* column $\%$ or mean (std. dev.)

** SEG 1 = "> 20\% living in poverty", SEG 2 = "Between $10 \%$ and $<20 \%$ of population living in poverty", SEG $3=$ "Between $5 \%$ and $<10 \%$ of population living in poverty", SEG $4=$ " $<5 \%$ of population living in poverty"

Most patients were diagnosed at ages 50 years and older (74.34\%). Non-Hispanic white patients comprised $83.67 \%$ and Non-Hispanic black patients comprised $8.77 \%$ of the cohort. Hispanic patients made up $7.56 \%$. Importantly, the distribution of race/ethnicity status was not statistically different between non-underweight and underweight.
Most patients were married (51.17\%) and had private health insurance (53.80\%). A large proportion (32.68\%) of patients were Medicare beneficiaries. Finally, on average, each patient had 0.65 comorbidities (or approximately 2 comorbidities per 3 patients) at diagnosis. No statistically significant difference between underweight and non-underweight was noted in SEG, marital status, insurance status, or number of comorbidities. 


\section{Clinical Profile}

Table 2 provides descriptive clinical profile for the cohort. The data also assessed the three most commonly tested biochemical markers in breast cancer: Estrogen Receptor (ER), Progesterone receptor (PR), and Human Epidermal Growth Factor Receptor 2 (HER-2).

Table 2: Tumor characteristics and treatment, and relation with underweight $(\mathrm{N}=1,368)$

\begin{tabular}{|c|c|c|c|c|c|}
\hline Variable & & Percentage & Non-underweight ${ }^{\star}$ & Underweight $^{*}$ & P-Value \\
\hline \multirow[t]{3}{*}{ ER } & - & 18.64 & 18.20 & 29.09 & 0.1151 \\
\hline & + & 76.54 & 77.00 & 65.45 & \\
\hline & Unknown & 4.82 & 4.80 & 5.45 & \\
\hline \multirow[t]{3}{*}{ PR } & - & 32.75 & 32.29 & 43.64 & 0.2006 \\
\hline & + & 61.99 & 62.45 & 50.91 & \\
\hline & Unknown & 5.26 & 5.26 & 5.45 & \\
\hline \multirow[t]{3}{*}{ HER2 } & - & 42.91 & 42.80 & 45.45 & 0.6140 \\
\hline & + & 11.40 & 11.58 & 7.27 & \\
\hline & Unknown & 45.69 & 45.62 & 47.27 & \\
\hline \multirow[t]{3}{*}{ Triple Negative } & No & 79.61 & 79.97 & 70.91 & 0.1168 \\
\hline & Yes & 6.29 & 6.32 & 5.45 & \\
\hline & Unknown & 14.11 & 13.71 & 23.64 & \\
\hline \multirow[t]{4}{*}{ Breast surgery } & No surgery & 2.19 & 2.13 & 3.64 & 0.0772 \\
\hline & Mastectomy & 40.13 & 39.98 & 43.64 & \\
\hline & Other surgery & 49.20 & 49.73 & 36.36 & \\
\hline & Unknown & 8.48 & 8.15 & 16.36 & \\
\hline \multirow[t]{3}{*}{ Hormone } & No & 74.34 & 74.26 & 76.36 & 0.5362 \\
\hline & Yes & 23.54 & 23.53 & 23.64 & \\
\hline & Unknown & 2.12 & 2.21 & 0.00 & \\
\hline \multirow[t]{3}{*}{ Radiation } & No & 66.59 & 66.49 & 69.09 & 0.2464 \\
\hline & Yes & 32.97 & 33.13 & 29.09 & \\
\hline & Unknown & 0.44 & 0.38 & 1.82 & \\
\hline \multirow[t]{3}{*}{ Chemo } & No & 54.02 & 53.92 & 56.36 & 0.8750 \\
\hline & Yes & 41.30 & 41.43 & 38.18 & \\
\hline & Unknown & 4.68 & 4.65 & 5.45 & \\
\hline \multirow[t]{4}{*}{ Stage } & Localized & 56.51 & 56.97 & 45.45 & 0.0007 \\
\hline & Regional & 33.77 & 33.89 & 30.91 & \\
\hline & Distant & 5.77 & 5.26 & 18.18 & \\
\hline & $\begin{array}{l}\text { Unknown/un- } \\
\text { staged }\end{array}$ & 3.95 & 3.88 & 5.45 & \\
\hline \multirow[t]{3}{*}{ Grade } & Well-differentiated & 19.08 & 19.27 & 14.55 & 0.1262 \\
\hline & $\begin{array}{l}\text { Moderately-differ- } \\
\text { entiated }\end{array}$ & 37.87 & 38.23 & 29.09 & \\
\hline & $\begin{array}{l}\text { Poorly- or un- } \\
\text { differentiated }\end{array}$ & 43.06 & 42.50 & 56.36 & \\
\hline \multirow[t]{3}{*}{ Histology } & Ductal & 83.77 & 83.93 & 80.00 & 0.4992 \\
\hline & Lobular & 10.67 & 10.66 & 10.91 & \\
\hline & Other & 5.56 & 5.41 & 9.09 & \\
\hline Tumor Size (mm) & & $24.40(22.62)$ & $24.24(22.45)$ & $28.05(26.35)$ & 0.2210 \\
\hline $\begin{array}{l}\text { Number of positive } \\
\text { nodes examined }\end{array}$ & & $1.29(2.98)$ & $1.27(2.95)$ & $1.95(3.63)$ & 0.1775 \\
\hline $\begin{array}{l}\text { Total number of } \\
\text { nodes examined }\end{array}$ & & $6.88(7.90)$ & $6.97(7.94)$ & $4.65(6.48)$ & 0.0329 \\
\hline
\end{tabular}


None of the distributions of the three markers differed significantly between underweight and non-underweight. "Triple negative" status (or the lack of all three markers) did not differ between the two groups significantly.

The distribution of stage of cancer at diagnosis was statistically different between the two groups (Underweight vs. Non-Underweight, $\mathrm{P}=0.0007$ ) in the bivariate relationship. Underweight patients were more likely to have distant $(18.18 \%$ vs. $5.26 \%$ ) or unknown stage of disease (5.45\% vs. $3.88 \%$ ) compared with their non-underweight counterparts. However, the pathologic grade did not differ significantly.

\section{Breast Cancer Outcomes}

The two-year survival of the cohort was estimated to be $94.7 \%$. The median follow-up time for those who died directly due to breast cancer was 709 days. Figure 1 (a) shows a Kaplan-Meier survival estimate by BMI category. The underweight category carried the poorest survival prognosis; and the survival for overweight or obese patients in our cohort was not significantly different from those of normal weight. As shown in Figures 1 (b) and 1 (c), when stratified by diagnosis stage, the lowest survival prognosis was still observed for underweight patients in localized as well as in regional and distant stages.

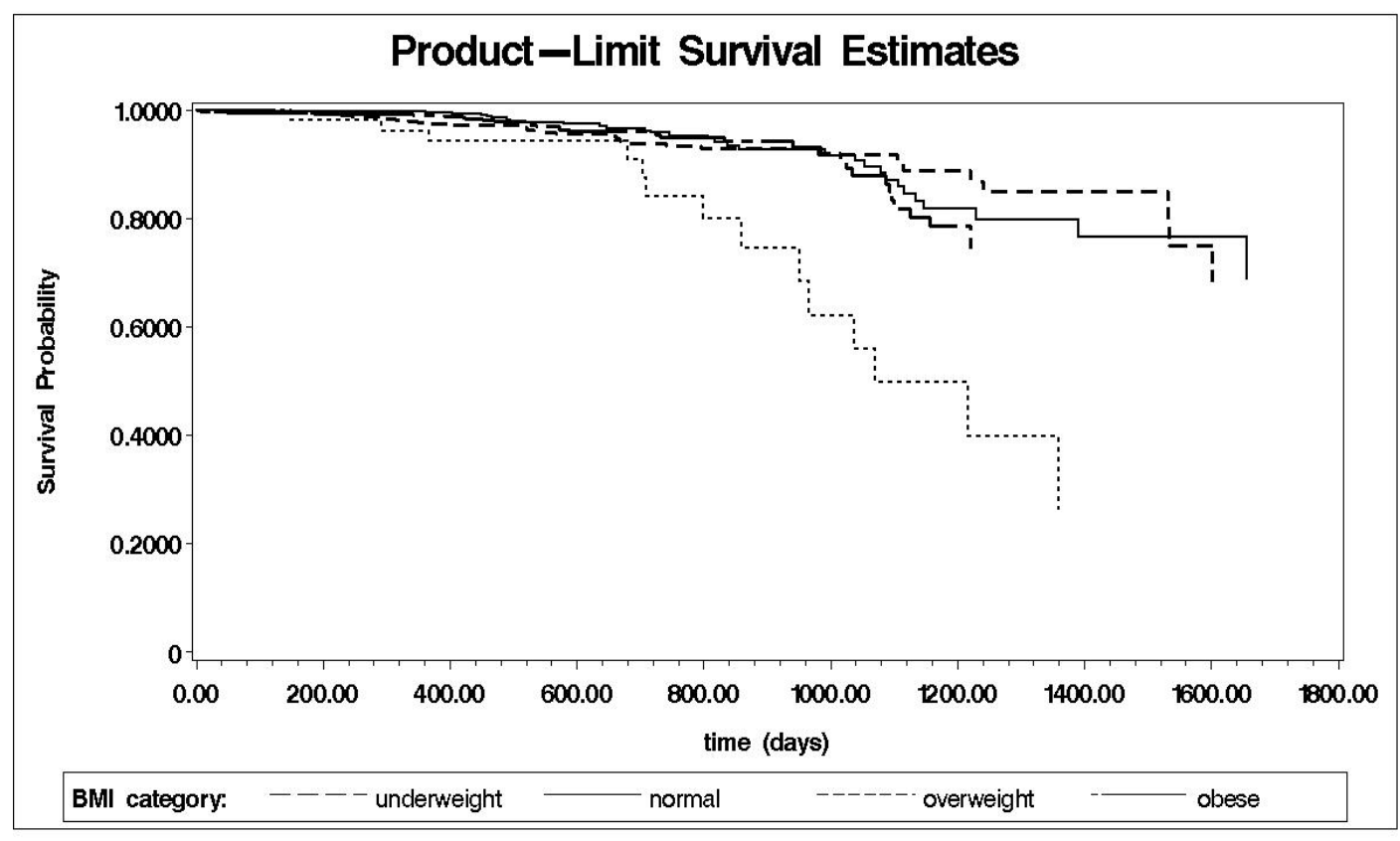

(a) Kaplan-Meier survival estimates for combined data $(\mathrm{N}=1368)$

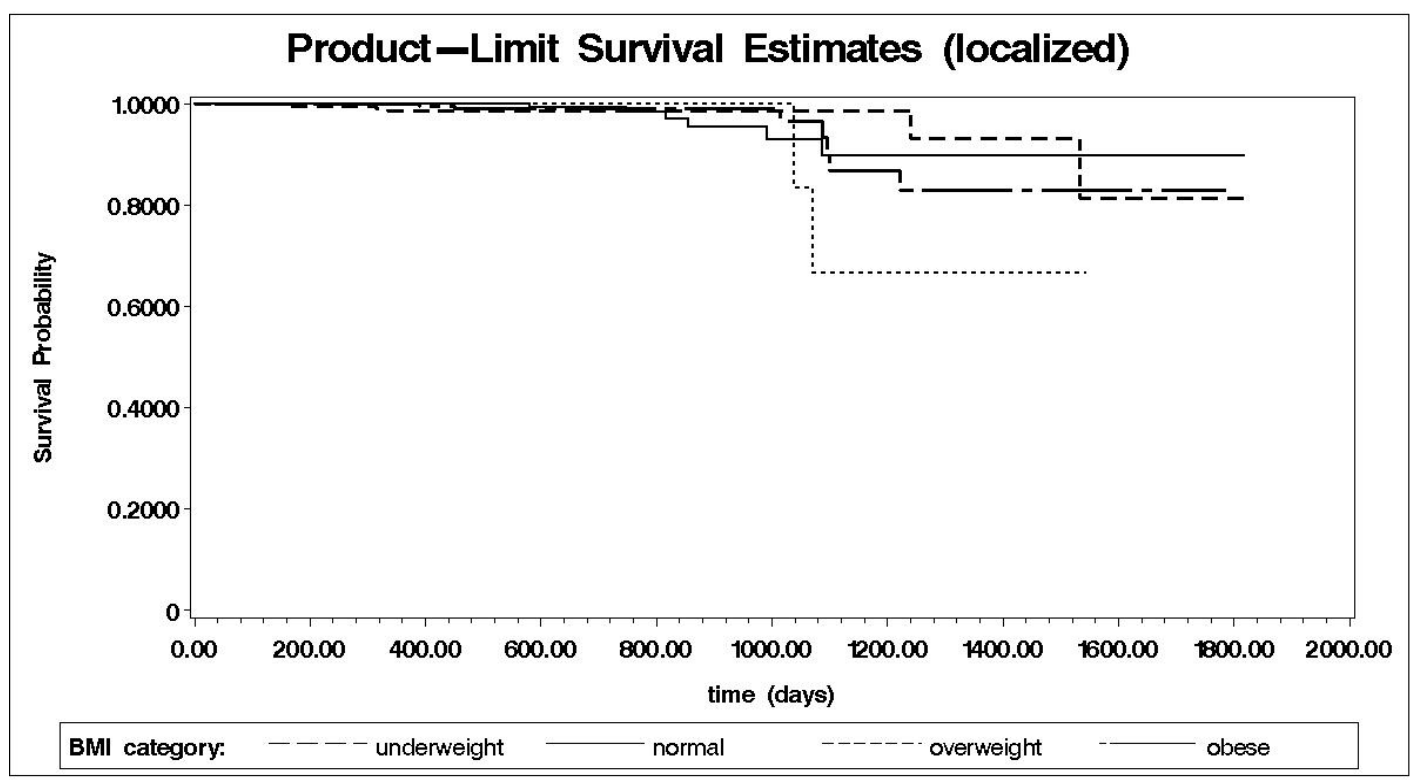

(b)

Kaplan-Meier survival estimates for localized stage $(\mathrm{N}=773)$ 


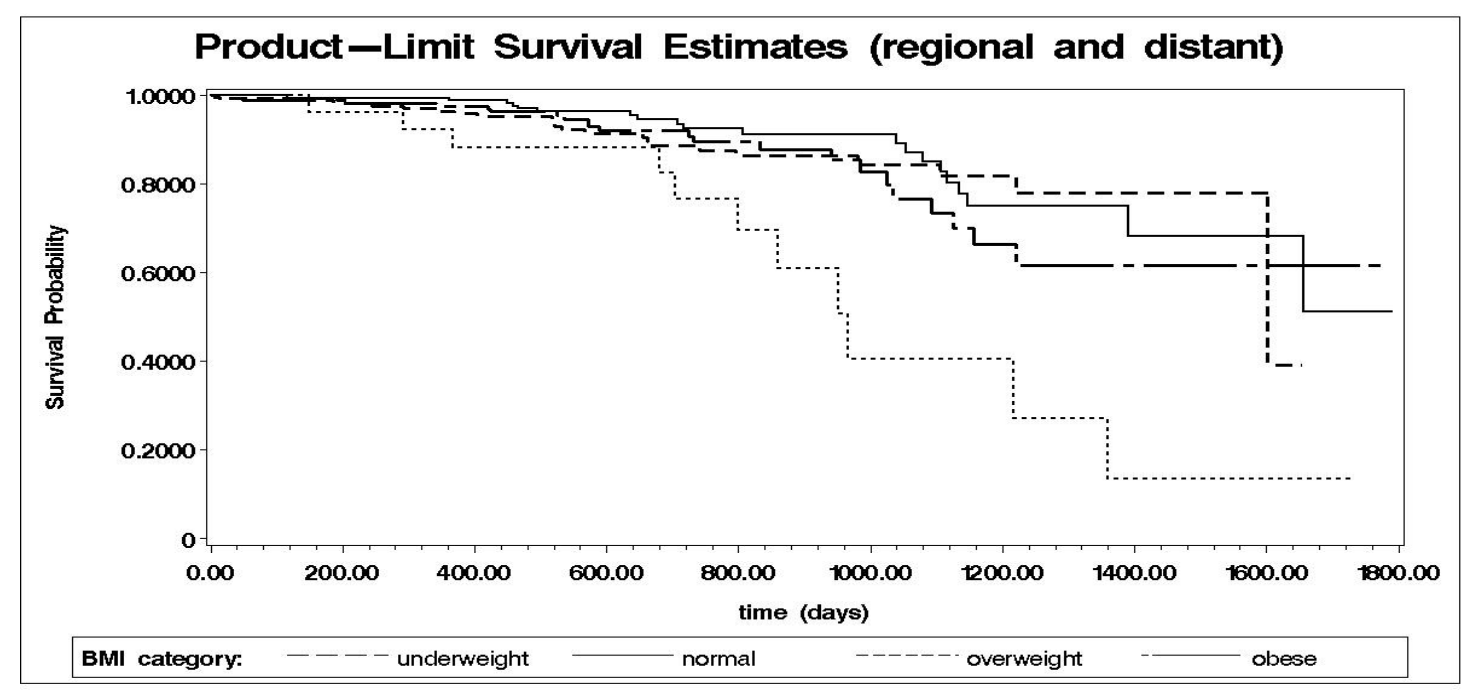

(c) Kaplan-Meier survival estimates for regional and distant stages $(\mathrm{N}=541)$

Figure 1 Kaplan-Meier survival estimates by BMI category.

This observation was consistent with test result based on the multivariate model after covariate adjustment.

Figure 2 compares Kaplan Meier survival estimates for Non-Hispanic white, Non-Hispanic black, and Hispanic patients. The race/ethnicity comparison in the figure indicates survival probability for Non-Hispanic black was the lowest for most of the study time. Although the bivariate racial comparison between Caucasian and African-American patients showed significant difference $(P=0.0465)$, the comparison among Non-Hispanic white, Non-Hispanic, black, and Hispanic patients was not significant $(\mathrm{P}=0.2522)$.

Table 3 presents a multivariate survival analysis of a multitude of variables that may influence time from diagnosis to death due to breast cancer.

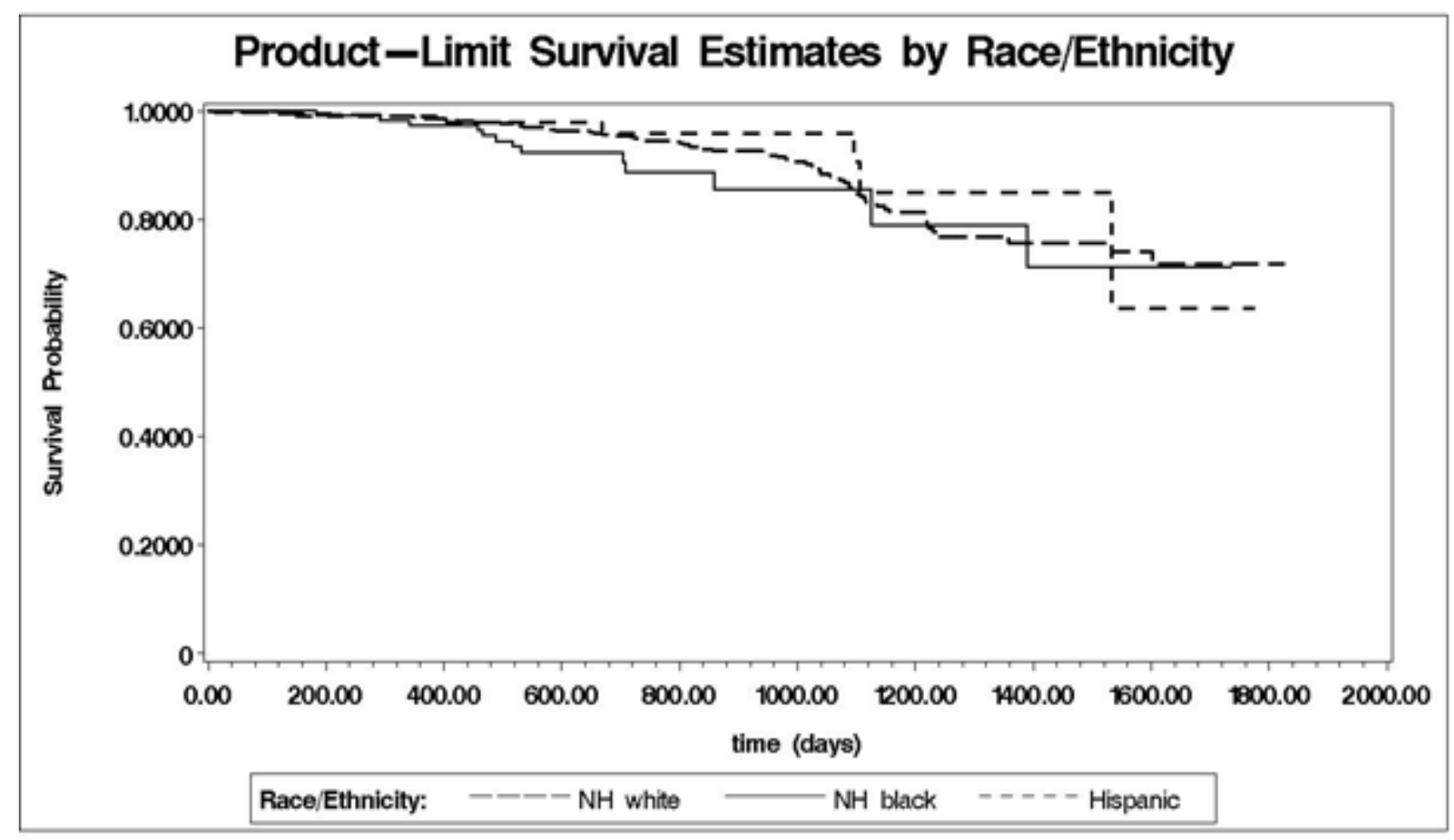

Figure 2: Kaplan-Meier Survival Estimate by Race/Ethnicity $(\mathrm{N}=1323)$ 
Table 3 multivariate survival analysis of time to breast cancer death $(\mathrm{N}=1,292)$

\begin{tabular}{|c|c|c|c|c|c|}
\hline Variable & & Hazard Ratio & \multicolumn{2}{|c|}{$95 \% \mathrm{CI}$} & P-Value \\
\hline \multirow{3}{*}{$\begin{array}{l}\text { BMI (vs. Normal } \\
\text { weight) }\end{array}$} & Underweight & 2.612 & 1.200 & 5.685 & 0.0156 \\
\hline & Overweight & 1.130 & 0.638 & 2.004 & 0.6752 \\
\hline & Obese & 1.710 & 0.965 & 3.030 & 0.0660 \\
\hline $\begin{array}{l}\text { Age at dx (vs. }<= \\
50)\end{array}$ & Age at $d x>50$ & 0.713 & 0.418 & 1.217 & 0.2152 \\
\hline \multirow{2}{*}{$\begin{array}{l}\text { Race/Ethnicity (vs. } \\
\text { NH white) }\end{array}$} & NH black & 1.272 & 0.598 & 2.704 & 0.5317 \\
\hline & Hispanic & 0.678 & 0.260 & 1.767 & 0.4260 \\
\hline \multirow{4}{*}{$\begin{array}{l}\text { Social economic } \\
\text { status (vs. SEG 4)* }\end{array}$} & SEG 1 & 0.574 & 0.258 & 1.280 & 0.1753 \\
\hline & SEG 2 & 0.592 & 0.310 & 1.131 & 0.1124 \\
\hline & SEG 3 & 0.902 & 0.497 & 1.637 & 0.7346 \\
\hline & Unknown & 0.370 & 0.062 & 2.221 & 0.2770 \\
\hline \multirow{2}{*}{$\begin{array}{l}\text { Married (vs. Mar- } \\
\text { ried) }\end{array}$} & Single & 1.071 & 0.670 & 1.711 & 0.7749 \\
\hline & Unknown & 0.628 & 0.139 & 2.843 & 0.5462 \\
\hline \multirow{3}{*}{$\begin{array}{l}\text { Insurance (vs. Pri- } \\
\text { vate insurance) }\end{array}$} & Not insured & 2.246 & 0.814 & 6.198 & 0.1181 \\
\hline & Medicaid & 1.766 & 0.930 & 3.354 & 0.0821 \\
\hline & Medicare & 2.422 & 1.394 & 4.208 & 0.0017 \\
\hline Total comorbidity & & 0.914 & 0.791 & 1.056 & 0.2206 \\
\hline \multirow{2}{*}{$\begin{array}{l}\text { Triple Negative (vs. } \\
\text { Non-Triple Nega- } \\
\text { tive) }\end{array}$} & Triple Negative & 8.514 & 3.940 & 18.400 & $<.0001$ \\
\hline & Unknown & 4.501 & 2.663 & 7.607 & $<.0001$ \\
\hline \multirow{3}{*}{$\begin{array}{l}\text { Breast surgery (vs. } \\
\text { No surgery) }\end{array}$} & Mastectomy & 2.848 & 0.899 & 9.016 & 0.0751 \\
\hline & Other surgery & 3.398 & 0.997 & 11.582 & 0.0505 \\
\hline & Unknown & 4.768 & 1.588 & 14.316 & 0.0054 \\
\hline \multirow{2}{*}{$\begin{array}{l}\text { Hormone (vs. No- } \\
\text { Hormone) }\end{array}$} & Hormone & 1.205 & 0.603 & 2.410 & 0.5976 \\
\hline & Unknown & 1.572 & 0.135 & 18.335 & 0.7181 \\
\hline \multirow{2}{*}{$\begin{array}{l}\text { Radiation (vs. No- } \\
\text { Radiation) }\end{array}$} & Radiation & 1.407 & 0.830 & 2.384 & 0.2043 \\
\hline & Unknown & 2.895 & 0.461 & 18.175 & 0.2567 \\
\hline \multirow{2}{*}{$\begin{array}{l}\text { Chemo (vs. No- } \\
\text { Chemo) }\end{array}$} & Chemo & 1.117 & 0.699 & 1.784 & 0.6446 \\
\hline & Unknown & 0.999 & 0.233 & 4.283 & 0.9994 \\
\hline \multirow{3}{*}{$\begin{array}{l}\text { Stage (vs. Local- } \\
\text { ized) }\end{array}$} & Regional & 1.883 & 0.931 & 3.809 & 0.0783 \\
\hline & Distant & 10.522 & 4.950 & 22.367 & $<.0001$ \\
\hline & $\begin{array}{l}\text { Unknown/un- } \\
\text { staged }\end{array}$ & 4.455 & 1.923 & 10.322 & 0.0005 \\
\hline
\end{tabular}




\begin{tabular}{|l|l|l|l|l|l|}
\hline $\begin{array}{l}\text { Grade (vs. Well- } \\
\text { differentiated) }\end{array}$ & $\begin{array}{l}\text { Moderately-differ- } \\
\text { entiated }\end{array}$ & 3.318 & 0.761 & 14.470 & 0.1104 \\
\hline $\begin{array}{l}\text { Poorly- or un- } \\
\text { differentiated }\end{array}$ & 4.109 & 0.955 & 17.682 & 0.0577 \\
\hline $\begin{array}{l}\text { Histology (vs. } \\
\text { Ductal) }\end{array}$ & Lobular & 1.299 & 0.659 & 2.561 & 0.4496 \\
\hline & Other & 0.621 & 0.290 & 1.329 & 0.2201 \\
\hline Tumor Size (mm) & 1.015 & 1.008 & 1.022 & $<.0001$ \\
\hline $\begin{array}{l}\text { Number of positive } \\
\text { nodes examined }\end{array}$ & 1.160 & 1.087 & 1.238 & $<.0001$ \\
\hline $\begin{array}{l}\text { Total number of } \\
\text { nodes examined }\end{array}$ & 0.957 & 0.919 & 0.995 & 0.0281 \\
\hline $\begin{array}{l}\text { Underweight } \mathrm{x} \text { NH } \\
\text { black }\end{array}$ & 0.425 & & & & 0.3993 \\
\hline $\begin{array}{l}\text { Underweight } \mathrm{x} \\
\text { Hispanic }\end{array}$ & 0.560 & & & 0.6320 \\
\hline
\end{tabular}

${ }^{*}$ SEG 1 = "> $20 \%$ living in poverty", SEG 2 = "Between $10 \%$ and $<20 \%$ of population living in poverty", SEG $3=$ "Between $5 \%$ and $<10 \%$ of population living in poverty", SEG $4=$ " $<5 \%$ of population living in poverty"

The breast cancer death rate for underweight patients was found to be 2.61 times that of normal weight patients $(\mathrm{P}=$ 0.0156). The BMI-race/ethnicity interactions were not statistically significant, indicating the disadvantageous effect for underweight patients was not different among the Non-Hispanic white, Non-Hispanic black, or Hispanic patients. However, patients who were Medicare beneficiaries had a 2.42-fold higher rate of death compared to those with health insurance other than Medicare or Medicaid $(\mathrm{P}=0.0017)$. No interaction between age at diagnosis or any other significant covariate (including BMI) met the 0.05 significance level for entry into the multivariate model, suggesting no significant difference between pre- and post-menopausal patients.

The p-value for the interaction between BMI and stage of disease did not meet the 0.05 significance level for entry into the model either, suggesting that the adjusted elevated risk for breast cancer death among underweight patients applied to all tested stages (local, regional, and distant).

The multivariate analysis (Table 3 ) found several other factors associated with higher breast cancer death rate including triple negative or unknown biomarker status, larger tumor size, having more positive nodes, having unknown surgery information, and having distant or unknown stage at diagnosis. Interestingly, having more nodes examined was associated with reduced breast cancer death rate. Notably, being overweight or obese was not found to be significantly associated with increased risk of breast cancer death in our model.

\section{Discussion}

This study suggests that being underweight $(\mathrm{BMI}<$ 19) is a poor predictive factor for female breast cancer patients. The risk of death in the underweight breast cancer patient group was significantly higher - with over a 2.6 fold increased risk of mortality (Table 3 ). The survival probabilities for the underweight group drop precipitously at approximately twoyears following diagnosis (Figure 1 (a)). Interestingly, despite patients with distant disease being more likely to be underweight than not $(18.18 \%$ vs. $5.26 \%)$, underweight patients also tended to have fewer nodes sampled on average (4.65 vs. $6.97, \mathrm{P}=0.0329)$ without a significant increase in rate of node-positivity $(\mathrm{P}=0.1775)$. As stated earlier, our data noted that the hazard ratio for underweight patients (compared with normal) did not vary across stage (not illustrated). This suggests that stage-related course of disease plays less of a role in the worsened prognosis of having a low BMI. Qualitative comparisons of trends in Figures 1 (b) and 1 (c) show that both low stage and high stage breast cancers have stronger association with higher mortality in underweight patients.

This study found that the effect of being underweight on increased mortality was equally distributed among the three race/ethnicity groups in our model. The breast cancer literature notes that African-Americans have worse outcomes in many measures including mortality [4]. In fact, it is noted that harmful predictive factors tend to disproportionately affect African-Americans. Our data is significant in the identification of a clinical and demographic risk factor that is ubiquitous among the cohort. The finding of this study suggests that underweight patients may be identified as a high-risk group assessed in all racial and ethnic populations. 
Moon et al., 2009 examined 24,698 Korean breast cancer patients and also found underweight status was an independent harmful prognostic factor for overall survival and breast cancer-specific survival [16]. Similarly, Caan et al., 2012 examined weight change and identified that a significant weight loss correlated with overall worse prognosis, particularly for those who were leaner at baseline [23]. Taken together, these data support the idea of an "obesity paradox" whereby being normal or even overweight is protective following the diagnosis of breast cancer but that being leaner is harmful. This phenomenon is more commonly described in chronic heart failure and other chronic wasting conditions [24-26].

A few limitations exist in our study. The data are retrospective in nature and although disease-specific data also were available, their accuracy could not be independently confirmed. Furthermore, in using only BMI as an indicator for weight status, the analyses ignore and possibly confound relationships with body composition, adiposity, and adipose distribution. However, BMI is accepted by the World Health Organization as an acceptable measure of stratification and classification [27]. While age at diagnosis was determined, menopause status in the patients was not. We opted for a strictly quantitative measure of menopausal status (with the age of 50 as the cutoff) because of variability in its clinical reporting. Finally, while our multivariate analysis and validation of underweight hazard by stage stratification attempt to reduce confounding, it is important to note the chance that patients in low BMI strata are leaner as a function of their poor health status, which in turn might reduce survival rates.

A major strength of our study is in our statistical analysis of all four BMI groups-underweight, normal, overweight, and obese-within the context of a single comparative multivariate analysis and K-M survival analysis plot. Many studies, such as Ewertz et al., 2010, Chen et al., 2012, and Huang et al., 1997, only assessed up to two of these groups $[11,14,18]$. Moon et al., 2009 notes how a common limitation in several studies of this field is in putting underweight patients in the same group as normal patients such as in Dawood et al., 2008 [16,28]. Although Moon et al., 2009 does study all of these groups individually, they also state that their patient sample is limited to a homogenous and ethnically similar pool that may not be generalizable to other ethnic groups [16]. As stated earlier, survival rates for breast cancer among the races in the United States may differ significantly [29]. By maintaining the heterogeneity of our serving population, this study has been able to identify underweight BMI as a cross-racial and cross-ethnic risk factor.

\section{Conclusion}

Breast cancer is a heterogeneous disease where biology meets demographics. This study suggests that a low BMI at diagnosis is a poor prognostic factor despite any strong demographic interplay. Specifically, the ubiquity of the effect of BMI on mortality suggests an underlying biologic process that crosses racial and ethnic boundaries. The identification of possible novel variable genetic, proteomic, and hormonal expression profiles in patients with breast cancer at various levels of BMI might further clarify the apparent paradox reported in the relationship of metabolic status to malignancy related mortality. Moving forward, the clinical translation and applicability of BMI to breast cancer may have substantial implications on breast cancer prognosis and treatment, especially considering the current climate of broad avocation for the multi-omic and metabolic consequences of malignancy. 


\section{References}

1) Mathers C, Fat DM, Boerma J (2008) The global burden of disease: 2004 update. World Health Organization.

2) Howlader N, Noone A, Krapcho M, et al. (2012) SEER cancer statistics review, 1975-2009 (vintage 2009 populations). Bethesda, MD: National Cancer Institute.

3) Smigal C, Jemal A, Ward E, Cokkinides V, Smith R, et al. (2006) Trends in breast cancer by race and ethnicity: Update 2006. CA: a cancer journal for clinicians 56:168-183.

4) Bradley CJ, Given CW, Roberts C (2002) Race, socioeconomic status, and breast cancer treatment and survival. J Natl Cancer Inst 94: 490-496.

5) Goodwin PJ, Ennis M, Pritchard KI, Trudeau ME, Koo J, et al. (2002) Fasting insulin and outcome in early-stage breast cancer: Results of a prospective cohort study. Journal of Clinical Oncology 20: 42-51.

6) Key TJ, Appleby PN, Reeves GK, Roddam A, Longcope C, et al. ( 2003) Body mass index, serum sex hormones, and breast cancer risk in postmenopausal women. J Natl Cancer Inst 95: 1218

7) Berclaz G, Li S, Price KN, Coates AS, Castiglione-Gertsch M, et al. (2004) Body mass index as a prognostic feature in operable breast cancer: The international breast cancer study group experience. Annals of Oncology 15: 875-884.

8) Kroenke CH, Chen WY, Rosner B, Holmes MD (2005) Weight, weight gain, and survival after breast cancer diagnosis. Journal of Clinical Oncology 23: 1370-1378.

9) Majed B, Moreau T, Senouci K, Salmon RJ, Fourquet A, et al. 2008) Is obesity an independent prognosis factor in woman breast cancer? Breast Cancer Res Treat 111: 329-342.

10) Caan BJ, Kwan ML, Hartzell G, Castillo A, Slattery ML, et al. (2008) Pre-diagnosis body mass index, post-diagnosis weight change, and prognosis among women with early stage breast cancer. Cancer Causes \& Control 19: 1319-1328.

11) Ewertz M1, Jensen MB, Gunnarsdóttir KÁ, Højris I, Jakobsen EH, et al. (2011) Effect of obesity on prognosis after early-stage breast cancer. Journal of clinical oncology 29: 25-31.

12) Protani M, Coory M, Martin JH (2010) Effect of obesity on survival of women with breast cancer: Systematic review and meta-analysis. Breast Cancer Res Treat 123: 627-635.

13) Ligibel JA, Goodwin PJ (2012) NEW and RENEW: Building the case for weight loss in breast cancer. Journal of Clinical Oncology 302294-2296.

14) Chen S, Chen C, Zhou Y, Zhou R, Yu K, et al. (2012) Obesity or overweight is associated with worse pathological response to neoadjuvant chemotherapy among chinese women with breast cancer. PloS one 7: e41380.

15) Suzuki R, Saji S, Toi M (2012) Impact of body mass index on breast cancer in accordance with the life-stage of women. Frontiers in oncology 2:123.

16) Moon H, Han W, Noh D ( 2009) Underweight and breast cancer recurrence and death: A report from the korean breast cancer society. Journal of Clinical Oncology. 27: 5899-5905.

17) Lahmann PH, Hoffmann K, Allen N, van Gils CH, Khaw KT, et al. (2004) Body size and breast cancer risk: Findings from the european prospective investigation into cancer and nutrition (EPIC). International journal of cancer 111: 762-771.

18) Huang Z, Hankinson SE, Colditz GA, Stampfer MJ, Hunter DJ, et al. (1997) Dual effects of weight and weight gain on breast cancer risk. JAMA: the journal of the American Medical Association 278: 1407-1411.
19) The AHRQ multiple chronic conditions research network: Project summary.

20) Elixhauser A, Steiner C, Harris DR, Coffey RM (1998) Comorbidity measures for use with administrative data. Med Care 36: 8-27.

21) Kay R (1986) Treatment effects in competing-risks analysis of prostate cancer data. Biometrics.:203-211.

22) Kalbfleisch JD, Prentice RL (2011) The statistical analysis of failure time data. Vol 360. John Wiley \& Sons.

23) Caan BJ, Kwan ML, Shu XO, Pierce JP, Patterson RE et al. ( 2012)

Weight change and survival after breast cancer in the after breast cancer pooling project. Cancer Epidemiology Biomarkers \& Prevention 21: $1260-1271$.

24) Curtis JP, Selter JG, Wang Y, Rathore SS, Jovin IS, et al. (2005) The obesity paradox: Body mass index and outcomes in patients with heart failure. Arch Intern Med 165:55-61.

25) Uretsky S, Messerli FH, Bangalore S, Champion A, Cooper-Dehoff RM, et al.(2007) Obesity paradox in patients with hypertension and coronary artery disease. Am J Med $120: 863-867$.

26) Lavie CJ, Milani RV, Ventura HO. (2009) Obesity and cardiovascular DiseaseRisk factor, paradox, and impact of weight loss. J Am CollCardiol. 53: 1925-1932.

27) (2000) Obesity: Preventing and managing the global epidemic. World Health Organ Tech Rep 894: 1-253.

28) Dawood S1, Broglio K, Gonzalez-Angulo AM, Kau SW, Islam R, et al. (2008) Prognostic value of body mass index in locally advanced breast cancer. Clinical Cancer Research 14: 1718-1725.

29) Clegg LX, Li FP, Hankey BF, Chu K, Edwards BK (2002) Cancer survival among US whites and minorities: A SEER (surveillance, epidemiology, and end results) program population-based study. Arch Intern Med.;162: 1985-1993. 
Submit your manuscript to a JScholar journal and benefit from:

I Convenient online submission

ฯ Rigorous peer review

- Immediate publication on acceptance

- Open access: articles freely available online

q High visibility within the field

- Better discount for your subsequent articles Submit your manuscript at http://www.jscholaronline.org/submit-manuscript.php 